\title{
Acceleration of Gonadal Maturation in Anadromous Maturing Sockeye Salmon by Gonadotropin-Releasing Hormone Analog Implantation
}

\author{
Masahiro Fukaya, ${ }^{*}{ }_{1}{ }^{* 5}$ Hiroshi Ueda, ${ }^{* 1, \dagger}$ Ayako Sato, ${ }^{* 1}$ \\ Masahide Kaeriyama, ${ }^{* 2, \dagger+}$ Hironori Ando, ${ }^{* 3}$ Yonathan Zohar, ${ }^{* 4}$ \\ Akihisa Urano, ${ }^{* 3}$ and Kohei Yamauchi*5
}

${ }^{*}$ Toya Lake Station for Environmental Biology, Faculty of Fisheries, Hokkaido University, Abuta, Hokkaido 049-5723, Japan

${ }^{*}$ National Salmon Resources Center, Fisheries Agency of Japan, Sapporo, Hokkaido 062-0922, Japan

${ }^{*}$ Division of Biological Sciences, Graduate School of Science, Hokkaido University, Sapporo, Hokkaido 060-0810, Japan

${ }^{*}$ Center of Marine Biotechnology, University of Maryland Biotechnology Institute, Baltimore, Maryland 21202, USA

${ }^{*}$ Department of Biology, Faculty of Fisheries, Hokkaido University, Hakodate, Hokkaido 041-0810, Japan

(Received May 26, 1998)

The effects of a three week intramuscular implantation of gonadotropin-releasing hormone analog (GnRHa) on gonadal maturation and changes in serum gonadal steroid hormone levels were examined in anadromous, maturing sockeye salmon Oncorhynchus nerka during the pre-spawning season. Spermiation occurred in both GnRHa-implanted and control males, but serum 17 $\alpha, 20 \beta$-dihydroxy-4-pregnen-3-one (DHP) levels in the implanted males were higher than in controls. No differences were found in serum testosterone (T) levels between GnRHa-implanted and control males. Serum 11-ketotestosterone (11KT) levels in control males increased for three weeks, but those in GnRHa-implanted males did not change. All GnRHa-implanted females ovulated completely for three weeks, while $25 \%$ of control females ovulated partially and the rest of females ovulated 17-24 days after sampling. The number of ovulated eggs of GnRHa-implanted females was greater than that of control females, and percentages of eyed eggs were not different between GnRHa-implanted and control females. Serum levels of DHP increased dramatically in GnRHa-implanted females, but those of T and estradiol-17 $\left(E_{2}\right)$ was similar to control females. These results confirm that $\mathrm{GnRHa}$ accelerates gonadal maturation of both sexes through elevation of serum DHP levels in maturing sockeye salmon.

Key words: Gonadotropin-releasing hormone analog, gonadal maturation, $17 \alpha, 20 \beta$-dihydroxy4-pregnen-3-one, anadromous sockeye salmon

In Japan, anadromous sockeye salmon Oncorhynchus nerka are not native, but they have been produced by the artificial release of smolts derived from lacustrine sockeye salmon in Lake Shikotsu into the Bibi River since 1983. ${ }^{1)}$ Since then, much of the propagation efforts have been focussed on the enhancement of anadromous sockeye salmon production, however, the population is still very low in Japan. One of the difficulties of sockeye salmon propagation is the long duration of rearing in the hatchery pond; sometimes four months are required prior to gonadal maturation. After hatching, juveniles must be reared for about 18 months to produce a $1^{+}$smolt. If an artificial treatment which could accelarate gonadal maturation would reduce rearing periods in maturing adult, it might be possible to produce a $0^{+}$smolt which would also be reduce rearing period of jeveniles.

Several new techniques have been introduced to accelerate gonadal maturation in many farmed fish. ${ }^{2)}$ Among them, gonadotropin-releasing hormone analog $(\mathrm{GnRHa})$ treatment is successfully used to reduce the spawning period in coho salmon O. kisutch, Atlantic salmon Salmo salar, and brown trout $S$. trutta. ${ }^{3)}$ The aim of the present study is to investigate whether a single, intramuscular implantation of GnRHa can accelerate gonadal maturation in anadromous, maturing sockeye salmon, and what kinds of gonadal steroid hormone, such as testosterone (T), 11ketotestosterone ( $11 \mathrm{KT}), 17 \alpha, 20 \beta$-dihydroxy-4-pregnen-3one (DHP) in males and T, estradiol-17 $\beta\left(E_{2}\right)$, DHP in females, will be influenced by the GnRHa implantation.

\footnotetext{
${ }^{\dagger}$ To whom correspondence should be addressed: Dr. Hiroshi Ueda, Toya Lake Station for Environmental Biology, Faculty of Fisheries, Hokkaido University, 122 Tsukiura, Abuta, Hokkaido 049-5723, Japan.

${ }^{\dagger}$ Present address: Department of Marine Sciences and Technology, School of Engineering, Hokkaido Tokai University, Sapporo, Hokkaido 005-0825, Japan.
} 


\section{Materials and Methods}

\section{Fish and GnRHa implantation}

Anadromous maturing sockeye salmon (three to five years old) were caught in the Bibi River (Chitose, Hokkaido, Japan) in the end of June 1996 and transported to the National Salmon Resources Center (Chitose, Hokkaido) where fish were kept in a rearing pond under natural photoperiod conditions without feeding. A total of 48 fish were randomly selected on September 6, anesthetized with $0.05 \%$ ethyl m-aminobezoate methanesulfonate (Nakarai Tesque, Kyoto, Japan), and tagged with an intraperitoneal pit tag. Nine males and seven females received a $2 \mathrm{~mm}$ implant containing $150 \mu \mathrm{g}$ of GnRHa, $\left[\right.$ Des-Gly ${ }^{10}, \mathrm{D}_{-} \mathrm{Ala}^{6}$, Pro $\left.^{9}\right] \mathrm{GnRH}$ ethyl amide in an ethylene-vinyl acetate copolymer matrix (AquaPharm Technologies Corp., Columbia, Maryland, USA). Seven females were administrated the implant containing $75 \mu \mathrm{g}$ of GnRHa. Sham operated eight males and eight females served as controls. GnRHa-implanted and control fish were sampled three weeks after the implantation. Three males and six females were sampled on the day of implantation and served as initial controls. At the time of sampling, the occurrence of spermiation and ovulation was checked by the application of gentle pressure on the abdomen. In females that had ovulated, the number of ovulated eggs was measured by counting egg number, and the percentage of 'eyed' eggs was calculated after artificial insemination which was couducted by routine procedure. Both at the time of implantation and sampling, serum samples for radioimmunoassay (RIA) of steroid hormones were collected from the caudal vasculature with $1 \mathrm{~m} l$ syringe and 24 gauge needle (Terumo, Tokyo, Japan). The pituitary glands were excised and preserved for molecular biological analysis of the expression of gonadotropin ( $\mathrm{GtH})$ subunit genes, and these results were published separately. ${ }_{4}^{4)}$

\section{RIA}

Serum levels of various steroid hormones were each measured by specific RIA methods; DHP, ${ }^{5)} \mathrm{E}_{2},{ }^{6} 11 \mathrm{KT},{ }^{7}$ and $T^{8)}$

\section{Statistics}

All data were expressed as means \pm SEM. Statistical analyses were calculated by one-way factorial analysis of vari- ance (ANOVA) followed by Fisher's PLSD.

\section{Results}

\section{Acceleration of Gonadal Maturation}

The effects of GnRHa implantation on gonadal maturity, number of ovulated eggs, and percentage of eyed eggs are shown in Table 1 . The gonadal maturity was divided into immature (no milt and no ovulated egg was observed) and mature (spermiation and ovulation were detected). The time of implantation was approximately 1.5-2 months prior to their natural spawning period of anadromous sockeye salmon, and the fish did not show any signs of spermiation or ovulation. Spermiation occurred in both control and GnRHa-implanted males at the time of sampling, three weeks later. All GnRHa-implanted females ovulated completely at the time of sampling. In contrast, two out of eight control females ovulated partially, and some matured eggs were not ovulated in these females. The rest of the females were reared to check the ovulation daily, and ovulated 17-24 days after sampling. The number of ovulated eggs of GnRHa-implanted females was significantly greater than that of two control females, but no differences were detected in the percentage of eyed eggs between GnRHa-implanted and control females (Table 1).

\section{Changes in Serum Steroid Hormone Levels}

Changes in serum T, $11 \mathrm{KT}$, and DHP levels in GnRHaimplanted and control males both at the time of implantation and sampling are presented in Fig. 1. There was no significant difference in serum $T$ levels between GnRHa-implanted and control males. Although serum IIKT levels in control males increased at the time of sampling, those in GnRHa-implanted males did not change. Serum DHP levels elevated significantly by the GnRHa implantation for three weeks.

Changes in serum T, $E_{2}$, and DHP levels in GnRHa-implanted and control females both at the time of implantation and sampling are shown in Fig. 2. No significant difference was detected in serum $T$ and $E_{2}$ levels between GnRHa-implanted and control females. Although serum DHP levels in two out of eight control females which ovulated partially were quite high, DHP in all GnRHa-implanted females was elevated significantly over control levels.

Table 1. Effects of GnRHa implantation on gonadal maturity, number of ovulated eggs, and percentage of eyed eggs in anadromous sockeye salmon

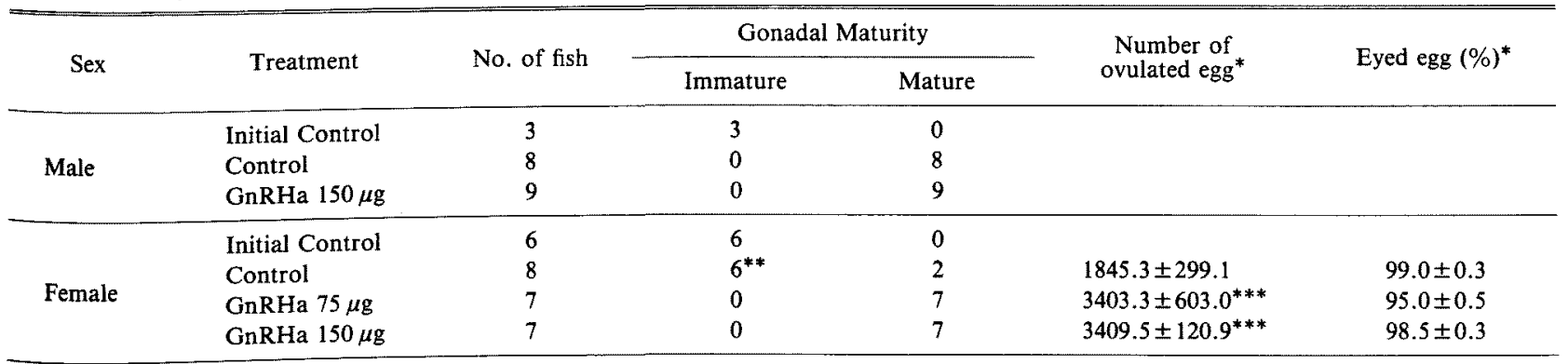

* Mean \pm SEM.

** These females ovulated 17-24 days later.

*** $P<0.01$ compared with control. 

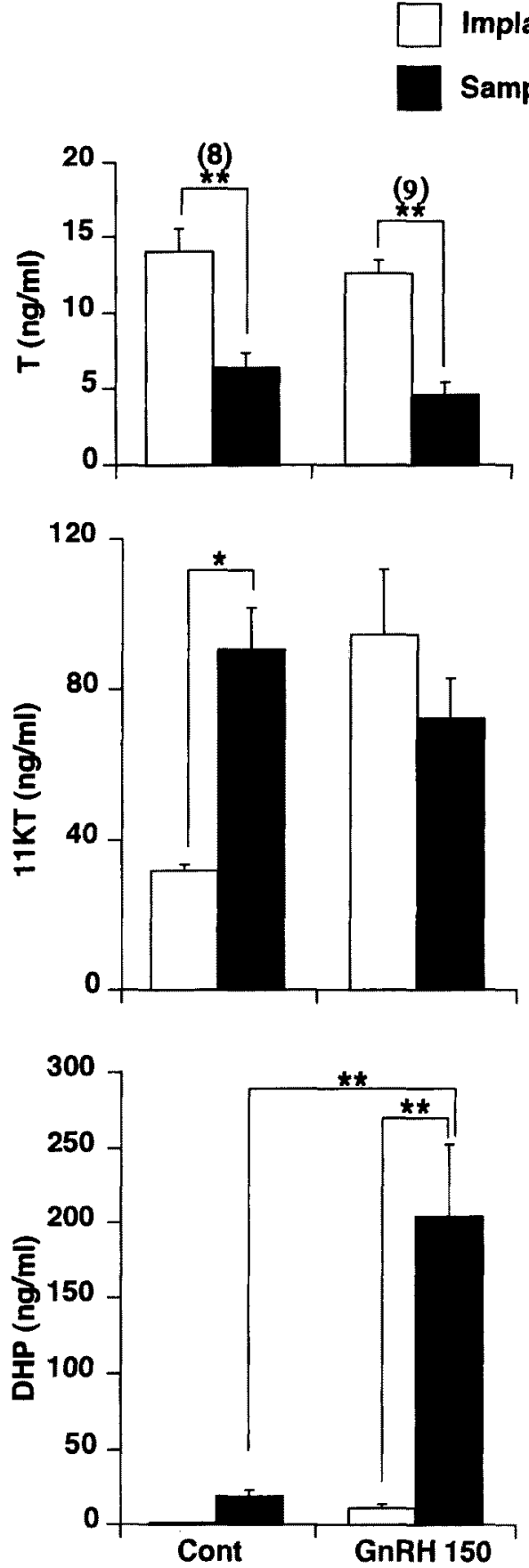

Fig. 1. Changes in serum steroid hormone levels of male, anadromous, maturing sockeye salmon.

White and black bars represent the mean \pm SEM of the indicated number of samples shown in parenthesis at the time of implantation and sampling, respectively. Significant differences at the $5 \%\left({ }^{*}\right)$ and $1 \%\left({ }^{* *}\right)$ levels is indicated. Cont, Control; GnRH $150,150 \mu \mathrm{g}$ of GnRHa implantation.

\section{Discussion}

An intramuscular implantation of GnRHa was highly effective in accelerating gonadal maturation in anadromous, maturing sockeye salmon of both sexes. Particularly in females, GnRHa implantation for three weeks in-
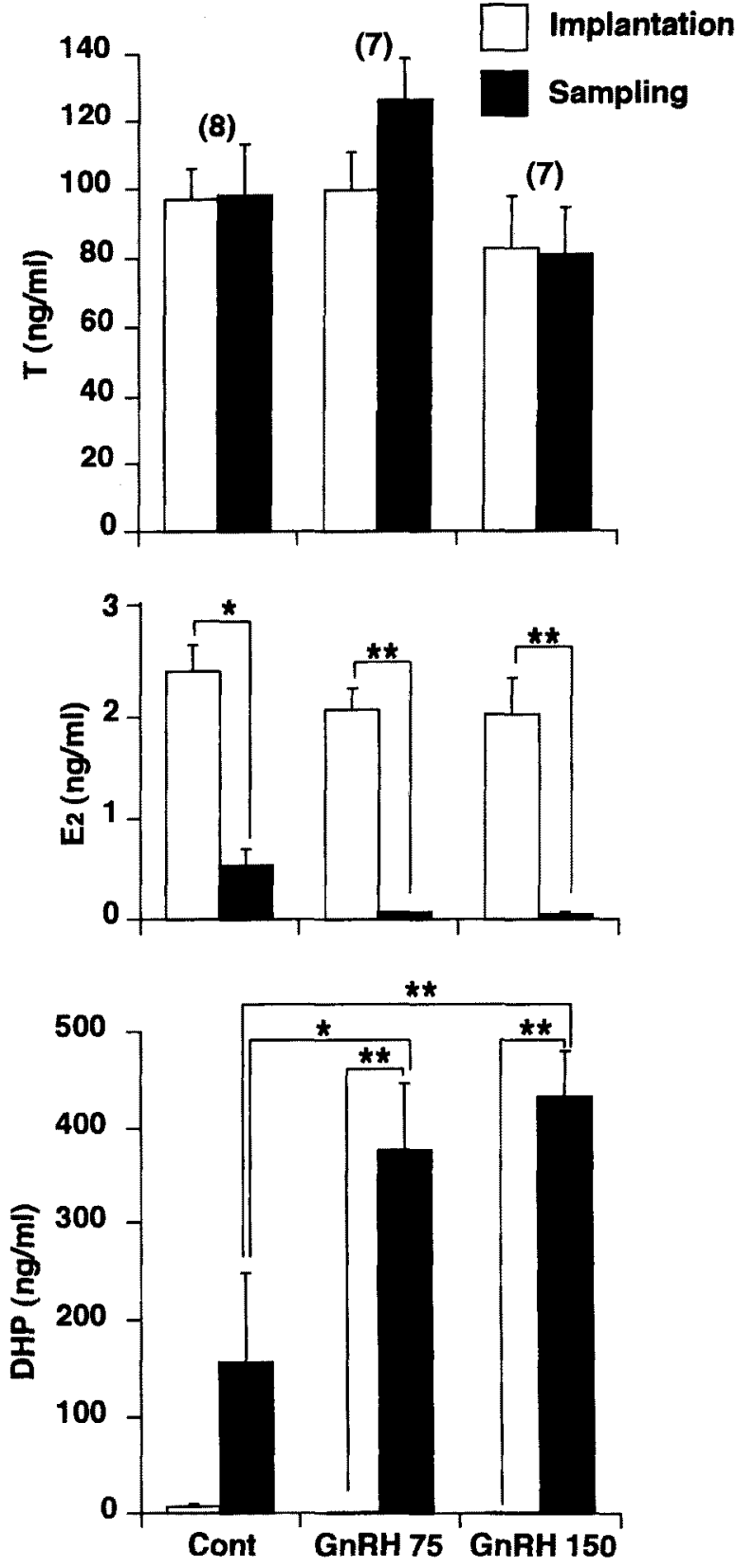

Fig. 2. Changes in serum steroid hormone levels of female anadromous maturing sockeye salmon.

White and black bars represent the mean \pm SEM of the indicated number of samples shown in parenthesis at the time of implantation and sampling, respectively. Significant differences at the $5 \%\left({ }^{*}\right)$ and $1 \%\left({ }^{* *}\right)$ levels are indicated. Cont, Control; GnRH 75, $75 \mu \mathrm{g}$ of GnRHa implantation; GnRH 150,150 $\mathrm{g}$ of GnRHa implantation.

duced complete ovulation, and also increased number of ovulated eggs ( 1.8 times higher than control). This enhancement seems likely to the result from a small quantity of ovulated eggs in two control femles. The other six control females ovulated completely 17-24 days after sampling. The total volume of milt was not measured in the present study. In Atlantic salmon, however, Gorent et al. ${ }^{3)}$ reported that GnRHa-implanted males produced seven times larger milt volume than untreated males. These results confirm the efficiency of GnRHa implantation in inducing 
gonadal maturation in anadromous maturing sockeye salmon of both sexes, and complete ovulation in females as is seen in farmed fishes. ${ }^{2)}$

Implantation of GnRHa caused significant elevation in serum levels of DHP in both sexes, but had no effect on levels of $\mathrm{T}$ and $11 \mathrm{KT}$ in males or $\mathrm{T}$ and $\mathrm{E}_{2}$ in females. DHP is identified as the maturation-inducing steroid in salmonids of both sexes, ${ }^{9}$ and its production is regulated by GtHs. The regulation of ovarian and testicular DHP production in vitro by $\mathrm{GtH} I$ and II were reported in coho salmon. ${ }^{10,11)}$ Expression of GtH subunit genes in pituitary glands of the same fish in the present study were examined and reported by Kitahashi et al. ${ }^{4)}$ The levels of GtH $\alpha$ and II $\beta$ mRNAs in $\mathrm{GnRHa}$-implanted fish were higher than those in control fish, but the level of GtHI $\beta$ mRNA showed no difference between GnRHa-implanted and control fish. These data suggest that GnRHa stimulates GtHII release from pituitary gland, and then GtHII enhances serum DHP levels in both sexes.

A single injection of partially purified chum salmon $\mathrm{GtH}$ (SGA) in non-spermiating amago salmon $O$. rhodurus approximately two months prior to the spawning season, was effective in inducing precocious spermiation.") The SGA injection caused different changes in serum DHP and $11 \mathrm{KT}$ levels; DHP levels peaked on the second day and thereafter declined, while 11KT levels increased on the second day and this increased level was sustained until the sixth day. It is interesting to compare changes in serum steroid hormone levels following GnRHa implantation and SGA injection. The differences of serum 11KT levels between GnRHa-implanted and control males suggested the possibility that GnRHa continuous stimulation might cause changes in the biosynthetic activity of DHP and $11 \mathrm{KT}$ during the pre-spawning period. A time course of sampling following GnRHa implantation should be carried out to clarify the effects of GnRHa on gonadal steroid hormone production.

A similar GnRHa implantation to lacustrine sockeye salmon in Lake Shikotsu also caused a dramatic increase in serum DHP levels in both sexes on average, however, individual GnRHa-implanted males, which rapidly returned to their natal hatchery, showed higher serum $\mathrm{T}$ levels and lower DHP levels than slower returning males. ${ }^{12)}$ The differences in the pre-existing condition of the testes may possibly explain the different response of DHP and T production. The effects of GnRHa implantation on gonadal steroid hormone production should be further examined by monitoring the steroid hormone biosynthetic pathway individually.

The present study clearly demonstrates the usefulness of GnRHa implantation in acceleration of gonadal maturation of both sexes and in possible advancement of artifical insemination in anadromous maturing sockeye salmon. This advancement makes it possible to reduce the duration of time to hatching of alevins, to promote growth of juvenile fry, and finally produce $0^{+}$smolts. These advantages will definitely contribute to the enhancement of anadromous sockeye salmon production in Japan.
Acknowledgments We are grateful to Messrs. K. Orito and H. Haruna (Toya Lake Station, Hokkaido University), and M. Fukuwaka and A. Wada (National Salmon Resources Center) for their assistance at the time of sampling. We also wish to express our thanks to Dr. D. S. Doering (AquaPharm Technologies Corp.) for the gift of the GnRHa implants, and Dr. J. B. K. Leonard (JSPS/NSF Postdoctoral Fellow) for the critical reading of the manuscript. The present study was supported in part by Grants-in-Aid from the Fisheries Agency of Japan, the Ministry of Education, Science, Sports and Culture, Japan, and the Takeda Science Foundation.

\section{References}

1) M. Kaeriyama, S. Urawa, and T. Suzuki: Anadromous sockeye salmon (Oncorhynchus nerka) derived from nonanadromous kokanee: Life History in Lake Toro. Sci. Rep. Hokkaido Salmon Hatchery, 46, 157-174 (1992).

2) Y. Zohar: New approaches for the manipulation of ovulation and spawning in farmed fish. Bull. Natl. Res. Inst. Aquacult. Suppl., 2, 43-48 (1996).

3) A. Goren, H. Gustafson, and D. Doering: Field trials demonstrate the efficacy and commercial benefit of a GnRHa implant to control ovulation and spermiation in salmonids, in "Proceedings of the Fifth International Symposium on the Reproductive Physiology of Fish" (ed. by F. W. Goetz and P. Thomas), The University of Texas at Austin Printing Department, Austin, USA, pp. 99-101 (1995).

4) T. Kitahashi, H. Ando, D. Alok, M. Kaeriyama, Y. Zohar, K. Yamauchi, H. Ueda, and A. Urano: GnRH analog stimulate gonadotropin II gene expression in maturing sockeye salmon. Zool. Sci., (in press).

5) G. Young, L. W. Crim, H. Kagawa, A. Kambegawa, and Y. Nagahama: Plasma $17 \alpha, 20 \beta$-dihydroxy-4-pregnen-3-one levels during sexual maturation of amago salmon (Oncorhynchus rhodurus): Correlation with plasma gonadotropin levels and in vitro production by ovarian follicles. Gen. Comp. Endocrinol., 51, 96-105 (1983).

6) H. Kagawa, G. Young, and Y. Nagahama Y: Estradiol-17 $\beta$ production in isolated amago salmon (Oncorhynchus rhodurus) ovarian follicles and stimulation by gonadotropin. Gen. Comp. Endocrinol., 47, 361-365 (1982).

7) H. Ueda, A. Kambegawa, and Y. Nagahama: Involvement of gonadotropin and steroid hormones in spermiation in the amago salmon, Oncorhynchus rhodurus, and goldfish, Carassius auratus. Gen. Comp. Endocrinol., 59, 24-30 (1985).

8) H. Ueda, O. Hiroi, K. Yamauchi, A. Hara, H. Kagawa, S. Adachi $S$, and $Y$. Nagahama: Changes in serum steroid hormone levels and in vitro steroid hormone production in the testes of male chum salmon Oncorhynchus keta during spawning migration. Nippon Suisan Gakkaishi, 57, 1111-1114 (1991).

9) Y. Nagahama: Endocrine regulation of gametogenesis in fish. Int. J. Dev. Biol., 38, 217-229 (1994).

10) J. P. Plansa, J. Athos, and P. Swanson: Regulation of ovarian steroidgenesis in vitro by gonadotropins during sexual maturation in coho salmon (Oncorhynchus kisutch), in "Proceedings of the Fifth International Symposium on the Reproductive Physiology of Fish" (ed. by F. W. Goetz and P. Thomas), The University of Texas at Austin Printing Department, Austin, USA, pp. 296-298 (1995).

11) J. P. Planas, and P. Swanson: Maturation-associated changes in the response of the salmon testis to the steroidogenic actions of gonadotropins (GTH I and GTH II) in vitro. Biol. Reprod., 52, 697-704 (1995).

12) A. Sato, H. Ueda, M. Fukaya, M. Kaeriyama, Y. Zohar, A. Urano, and $\mathrm{K}$. Yamauchi: Sexual differences in homing profiles and shortening of homing duration by gonadotropin-releasing hormone analog implantation in lacustrine sockeye salmon (Oncorhynchus nerka) in Lake Shikotsu. Zool. Sci., 14, 1009-1014 (1997). 